\title{
Staphylococcus aureus gene expression in a rat model of infective endocarditis
}

\author{
Frank Hanses ${ }^{1,2^{*}}$, Christelle Roux ${ }^{3}$, Paul M Dunman ${ }^{3}$, Bernd Salzberger ${ }^{2}$ and Jean C Lee
}

\begin{abstract}
Background: Diabetes mellitus is a frequent underlying comorbidity in patients with Staphylococcus aureus endocarditis, and it represents a risk factor for complications and a negative outcome. The pathogenesis of staphylococcal endocardial infections in diabetic hosts has been poorly characterized, and little is known about S. aureus gene expression in endocardial vegetations.

Methods: We utilized a rat model of experimental S. aureus endocarditis to compare the pathogenesis of staphylococcal infection in diabetic and nondiabetic hosts and to study the global S. aureus transcriptome in endocardial vegetations in vivo.

Results: Diabetic rats had higher levels of bacteremia and larger endocardial vegetations than nondiabetic control animals. Microarray analyses revealed that $61 \mathrm{~S}$. aureus genes were upregulated in diabetic rats, and the majority of these bacterial genes were involved in amino acid and carbohydrate metabolism. When bacterial gene expression in vivo (diabetic or nondiabetic endocardial vegetations) was compared to in vitro growth conditions, higher in vivo expression of genes encoding toxins and proteases was observed. Additionally, genes involved in the production of adhesins, capsular polysaccharide, and siderophores, as well as in amino acid and carbohydrate transport and metabolism, were upregulated in endocardial vegetations. To test the contribution of selected upregulated genes to the pathogenesis of staphylococcal endocarditis, isogenic deletion mutants were utilized. A mutant defective in production of the siderophore staphyloferrin B was attenuated in the endocarditis model, whereas the virulence of a surface adhesin $(\triangle s d r C D E)$ mutant was similar to that of the parental S. aureus strain.
\end{abstract}

Conclusions: Our results emphasize the relevance of diabetes mellitus as a risk factor for infectious endocarditis and provide a basis for understanding gene expression during staphylococcal infections in vivo.

\section{Background}

Infective endocarditis is an invasive human disease with an estimated incidence of 5 to 16 cases per 100,000 person-years $[1,2]$ and an in-hospital mortality rate of $18 \%$ to $20 \%$ [3]. Staphylococcus aureus is the most frequent etiologic agent of endocarditis in developed countries $[1,3]$ and is associated with an aggressive disease course, a poor outcome, and complications such as local destruction of valve tissue, septic emboli, and persistent bacteremia [3]. Antibiotic resistance is widespread among

\footnotetext{
* Correspondence: frank.hanses@ukr.de

'Channing Laboratory, Department of Medicine, Brigham and Women's

Hospital and Harvard Medical School, Boston, MA 02115, USA

${ }^{2}$ Department of Internal Medicine I, University Hospital Regensburg,

Franz-Josef-Strauss Allee 11, Regensburg 93049, Germany

Full list of author information is available at the end of the article
}

clinical S. aureus isolates, and bacteremia due to methicillin-resistant $S$. aureus (MRSA) often requires the use of expensive or less effective antibiotics.

Risk factors for endocarditis include injection drug use, prosthetic heart valves, structural heart defects, and comorbidities, such as diabetes $[2,4,5]$. Among patients with endocarditis, $S$. aureus is more frequently isolated from individuals with diabetes than those with no diabetes [6]. Moreover, patients with diabetes have higher mortality due to $S$. aureus endocarditis than patients without diabetes [7]. Although defects in the immune response to bacterial infections in patients with diabetes have been postulated [8], the mechanism(s) behind the increased susceptibility to invasive $S$. aureus infections remain elusive. 
Several S. aureus virulence factors have been implicated in the pathogenesis of endocarditis. Fibronectinbinding protein $\mathrm{A}$ (FnBPA) and clumping factor $\mathrm{A}$ (ClfA) mediate staphylococcal adherence to endothelial cells $[9,10]$. Damage to cardiac valves results in exposure of the subendothelial matrix and deposition of fibrin and platelets at the site of endovascular injury. ClfA plays a role in $S$. aureus binding to platelets - an interaction that is critical to the induction of staphylococcal endocarditis [11]. Staphylococci recovered from rabbit endocardial vegetations are highly encapsulated [12]. Other factors shown to play a role in the pathogenesis of endocarditis include gene regulators such as sar and agr [13], alpha toxin [14], the sortase enzyme SrtA [15], and the proline permease PutP [16].

Although numerous studies have described in vivo expression of selected staphylococcal genes $[17,18]$ ), few have investigated overall patterns of bacterial gene expression in an infected host. Analyses of global gene expression patterns have focused primarily on in vitro conditions, and few descriptions of the S. aureus transcriptome during the course of an infection have been reported $[19,20]$. The $S$. aureus transcriptional profile during growth in broth culture correlates poorly with gene expression in mammalian infections, and further work to characterize $S$. aureus gene regulation in vivo is necessary [21].

Our goal was to assess the impact of concurrent diabetes mellitus on the course of endocarditis in a welldefined experimental infection model, to compare the transcriptional profile of $S$. aureus in established endocardial vegetations of diabetic and nondiabetic hosts versus growth in vitro, and to study the role of genes highly expressed in vivo as virulence factors in S. aureus endocarditis.

\section{Methods}

\section{Bacteria and culture conditions}

To evaluate differences in endocarditis disease severity and for microarray analyses, diabetic or nondiabetic rats were challenged with the MRSA strain COL. To establish the role of selected genes in the pathogenesis of $S$. aureus endocarditis, we utilized $S$. aureus strain Newman and its isogenic mutants. Newman $\triangle s d r C D E$ [22] was kindly provided by Dr Timothy Foster, and Newman $\Delta s b n E$ [23] was generously provided by Dr David Heinrichs. Staphylococci were cultivated in tryptic soy broth (TSB) to the mid-logarithmic phase, washed in phosphate-buffered saline (PBS), and diluted to yield an inoculum of approximately $3 \times 10^{4} \mathrm{CFU} /$ rat.

\section{Rat endocarditis model}

This study was carried out in strict accordance with the recommendations in the Guide for the Care and Use of
Laboratory Animals of the National Institutes of Health. All animal experiments were approved by the Harvard Medical School Standing Committee on Animals or by the local authorities in Regensburg. Diabetes was induced one day prior to surgery by injecting male Sprague-Dawley rats (approximately 200 g; Charles River Laboratories, Wilmington, MA, USA, and Sulzfeld, Germany) in the tail vein with streptozotocin $(60 \mathrm{mg} / \mathrm{kg})$; control rats received citrate buffer only [24]. Animals were considered diabetic if blood glucose levels exceeded 250 $\mathrm{mg} / \mathrm{dl}$ after $24 \mathrm{~h}$.

The rat model of catheter-induced $S$. aureus endocarditis was described previously [25]. Catheterized diabetic or nondiabetic rats were challenged intravenously with approximately $3 \times 10^{4} \mathrm{CFU}$ S. aureus $48 \mathrm{~h}$ after surgery. Heparinized blood was collected daily from each animal by tail vein puncture and plated quantitatively. Surviving rats were euthanized on day 3 after challenge. Catheter tips (about $2 \mathrm{~cm}$ ) were removed, sonicated in PBS, and plated quantitatively. The kidneys, spleens, and aortic valve vegetations were weighed, homogenized, and cultured quantitatively. Homogenized vegetations were pelleted, suspended in RNAprotect Bacteria Reagent (Qiagen, Hilden, Germany) overnight at $4^{\circ} \mathrm{C}$, and stored at $-80^{\circ} \mathrm{C}$.

\section{RNA isolation}

Total RNA was prepared from homogenized vegetation pellets from single animals after digestion with $4 \mathrm{mg} / \mathrm{ml}$ proteinase K (Qiagen) for $30 \mathrm{~min}$. S. aureus COL cells were lysed with $0.5 \mathrm{ml}$ zirconia silica beads (Fisher Scientific, Waltham, MA, USA) in a dental amalgamator, and RNA was purified with the RNeasy Mini kit (Qiagen), treated with DNase I (Invitrogen, Grand Island, $\mathrm{NY}$ ), and stored at $-80^{\circ} \mathrm{C}$. RNA integrity and absence of eukaryotic RNA were confirmed by denaturing gel electrophoresis. RNA from planktonic cultures was isolated from bacteria harvested from mid-logarithmic $(5 \mathrm{~h})$ or stationary phase $(18 \mathrm{~h}) \mathrm{TSB}$ cultures incubated at $37^{\circ} \mathrm{C}$.

\section{Microarray analysis}

Amplification of $10 \mathrm{ng}$ RNA samples using ExpressArt Nanokits (Amsbio, Cambridge, MA) was performed according to the manufacturer's recommendations for bacterial mRNA amplification, except that the final transcription and labeling step was performed using Enzo BioArray HighYield RNA Transcript Labeling kits (Farmingdale, NY, USA) to incorporate biotinylated ribonucleotides into final RNA products. Each biotinylated RNA sample $(1 \mu \mathrm{g})$ was hybridized to Affymetrix $S$. aureus GeneChips (Santa Clara, CA, USA) following the manufacturer's recommendations for antisense prokaryotic arrays. GeneChips were washed, stained, and scanned, as previously described 
[26]. Each condition (diabetic or nondiabetic rat and logarithmic or stationary phase culture) was analyzed in duplicate. GeneChip signal intensity values for each qualifier were then normalized, averaged, and analyzed using GeneSpring 6.2 software (Silicon Genetics, Redwood City, CA, USA), as described [26]. Genes were considered to be induced in a vegetation if they were determined to be present by Affymetrix algorithms in the endocarditis condition, and if they exhibited a greater than two-fold increase in RNA titer (Student's $t$-test; $P \leq 0.05$ ) compared to the corresponding planktonic growth condition. Genes were considered downregulated in the vegetations if they were present in either planktonic condition and had an expression level less than $50 \%$ of that observed in the corresponding planktonic growth condition (Student's $t$-test; $P \leq 0.05)$. All GeneChip data have been deposited in the National Center for Biotechnology Information (NCBI) Gene Expression Omnibus (GEO) microarray repository under accession number [GEO:GSE62390].

\section{Quantitative PCR}

cDNA was synthesized using the AffinityScript Multiple Temperature cDNA Synthesis Kit (Agilent Technologies, Santa Clara, CA, USA), $5 \mu$ l of hot-denatured DNAfree RNA, and 100 pmol of random hexamer primers. Products were precipitated in ethanol, resuspended in diethylpyrocarbonate-water, and stored at $-20^{\circ} \mathrm{C}$. Quantification was performed using a LightCycler 2.0 apparatus (Roche Diagnostics, Mannheim, Germany) and QuantiTect SYBR Green PCR Kits (Qiagen), using $2 \mu \mathrm{l}$ of cDNA and 20 pmol of each primer. Primers (Additional file 1: Table S1) were synthesized by Eurofins MWG (Ebersberg, Germany).

\section{Statistical analysis}

Student's $t$-tests were used to compare gene expression data. Mann-Whitney $U$ tests were performed to compare quantitative culture data, and the log rank test was used to compare survival distributions. A $P$-value of $\leq 0.05$ was considered significant.

\section{Results}

Infective endocarditis was more severe in diabetic than nondiabetic rats

To assess the impact of diabetes on the pathogenesis of $S$. aureus endocarditis induced by strain COL, we compared the infection in rats with streptozotocin-induced diabetes to that of nondiabetic rats. All rats showed increasing bacteremia levels from days 1 to 3 (Figure 1A). Diabetic rats had significantly higher levels of bacteremia than nondiabetic rats on days 2 and 3 after inoculation (Figure 1A). Diabetic rats had larger endocardial
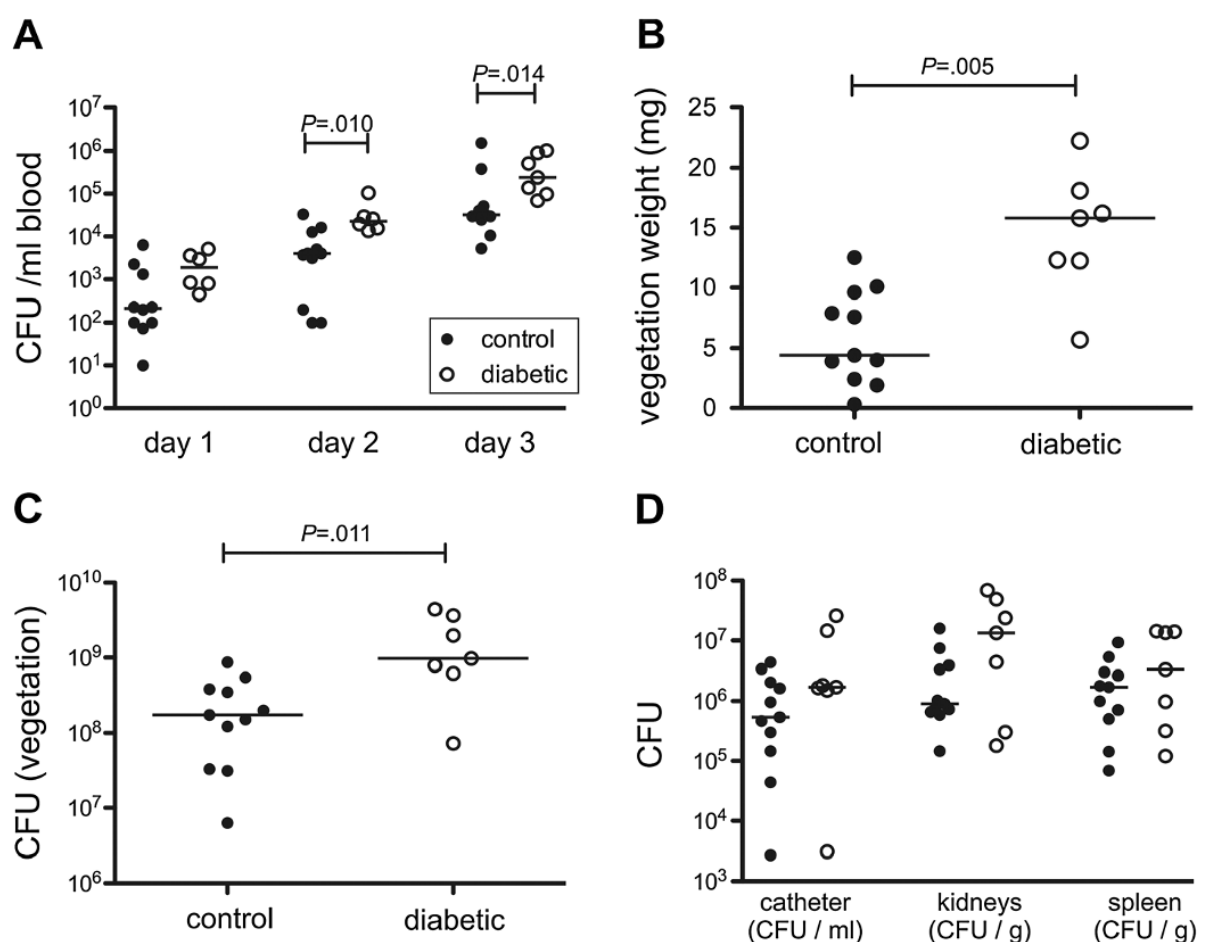

D

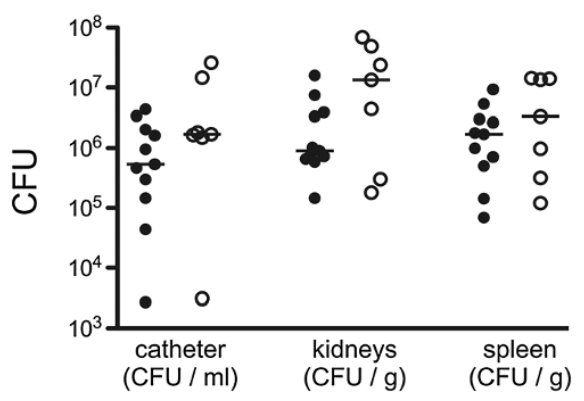

Figure 1 Endocarditis was more severe in diabetic rats than in nondiabetic rats. (A) Diabetic animals had significantly higher levels of bacteremia on day 2 and day 3 after bacterial challenge. (B) Diabetic animals had larger vegetations, and (C) the vegetations were associated with a significantly higher bacterial burden. (D) The bacterial burden in the kidneys, spleens, and catheters were not significantly different between diabetic and nondiabetic rats. 
vegetations (Figure $1 \mathrm{~B}$ ) with significantly more bacteria per vegetation (Figure 1C). We also observed trends toward elevated bacterial burdens in kidneys, spleens, and explanted catheters from diabetic rats compared with nondiabetic rats (Figure 1D), although these differences did not reach statistical significance.

\section{Differential S. aureus gene expression in diabetic and nondiabetic rats}

We hypothesized that staphylococcal gene expression might be influenced by hyperglycemia in the diabetic host. Microarray analyses, however, indicated that overall gene expression was similar between the two groups of animals challenged with $S$. aureus COL. A total of 61 transcripts were more highly expressed under diabetic in vivo conditions (selected genes are presented in Table 1). Most of these genes were associated with metabolic processes such as amino acid and carbohydrate metabolism or cell homeostasis. LightCycler analyses confirmed higher expression of ATP synthase atpA (12.9 \pm 4.3 fold) and glyceraldehyde dehydrogenase gapA (10.6 \pm 2.1 fold) in vegetations from diabetic rats compared with nondiabetic rats. Only two genes (SACOL1895 and a $102 \mathrm{bp}$ fragment, both with unknown functions) had significantly lower expression in the vegetations of diabetic compared with nondiabetic animals.

Table 1 List of selected genes differentially expressed in diabetic and nondiabetic vegetations

\begin{tabular}{|c|c|c|c|}
\hline Gene & Diabetic versus nondiabetic & Gene product & Functional group \\
\hline$a c p S$ & 2.6 & holo-(acyl-carrier-protein) synthase & Lipid transport and metabolism \\
\hline alr & 2.9 & alanine racemase & Cell wall/membrane biogenesis \\
\hline $\arg G$ & 10.0 & argininosuccinate synthase & Amino acid transport and metabolism \\
\hline $\operatorname{argH}$ & 15.3 & argininosuccinate lyase & Amino acid transport and metabolism \\
\hline $\operatorname{atp} A$ & 3.8 & ATP synthase F1, alpha subunit & Energy production and conversion \\
\hline atpE & 2.4 & ATP synthase F0, $\mathrm{C}$ subunit & Energy production and conversion \\
\hline atpH & 3.3 & ATP synthase F1, delta subunit & Energy production and conversion \\
\hline cap5F & 2.5 & capsular polysaccharide biosynthesis & Cell wall/membrane biogenesis \\
\hline cap5K & 3.5 & capsular polysaccharide biosynthesis & Cell wall/membrane biogenesis \\
\hline$c c r B$ & 2.0 & cassette chromosome recombinase $B$ & \\
\hline$d n a E$ & 2.6 & DNA polymerase III, alpha subunit & Nucleotide metabolism, replication, recombination \\
\hline$f a b D$ & 3.3 & malonyl CoA-acyl carrier protein transacylase & Lipid transport and metabolism \\
\hline gapA & 4.4 & glyceraldehyde 3-P dehydrogenase & Carbohydrate transport and metabolism \\
\hline geh & 2.3 & glycerol ester hydrolase & Miscellaneous \\
\hline$g l p P$ & 2.2 & glycerol uptake operon regulatory protein & Transcription, translation and post-translational modification \\
\hline glys & 4.2 & glycyl-tRNA synthetase & Transcription, translation and post-translational modification \\
\hline hemX & 2.2 & hem $X$ protein & Transcription, translation and post-translational mod. \\
\hline $\operatorname{infB}$ & 2.6 & translation initiation factor IF-2 & Transcription, translation and post-translational modification \\
\hline$k d p E$ & 2.4 & DNA-binding response regulator & Regulatory \\
\hline $\operatorname{lig} A$ & 2.3 & DNA ligase, NAD-dependent & Nucleotide metabolism, replication, recombination \\
\hline menD & 2.1 & carboxylic acid synthase & Coenzyme transport and metabolism \\
\hline moeA & 3.4 & molybdopterin biosynthesis, putative & Coenzyme transport and metabolism \\
\hline$n r d F$ & 2.7 & ribonucleoside-diphosphate reductase 2 & Nucleotide metabolism, replication, recombination \\
\hline pls & 3.7 & plasmin-sensitive protein & Virulence \\
\hline recQ & 2.8 & ATP-dependent DNA helicase & Nucleotide metabolism, replication, recombination \\
\hline $\operatorname{rex} A$ & 3.2 & exonuclease & Nucleotide metabolism, replication, recombination \\
\hline ribD & 2.7 & riboflavin biosynthesis protein & Coenzyme transport and metabolism \\
\hline ribE & 2.4 & riboflavin synthase, alpha subunit & Coenzyme transport and metabolism \\
\hline ruvB & 2.2 & Holliday junction DNA helicase & Nucleotide metabolism, replication, recombination \\
\hline $\operatorname{sas} A$ & 4.8 & LPXTG cell wall surface protein & Virulence \\
\hline $\operatorname{sirC}$ & 3.1 & iron $A B C$ transporter, permease protein & Inorganic ion transport and metabolism \\
\hline ureC & 7.5 & urease, alpha subunit & Amino acid transport and metabolism \\
\hline
\end{tabular}




\section{Differential S. aureus gene expression in endocardial vegetations}

To compare $S$. aureus gene expression in vivo versus in vitro, we isolated bacterial RNA from endocardial vegetations on day 3 post-challenge and from staphylococci in the logarithmic or stationary growth phase. Overall gene expression in diabetic and nondiabetic animals was similar, but differences between in vivo and in vitro growth conditions tended to be more pronounced in vegetations from diabetic hosts (Table 2). Microarray analyses revealed that 116 and 109 genes were more highly expressed in vegetations from nondiabetic and diabetic rats, respectively, compared with both planktonic conditions; 98 and 103 genes were more highly expressed in vivo compared with logarithmic phase cultures only; and 81 and 65 genes were more highly expressed in vivo compared with stationary phase cultures only. Additionally, we observed that 223 and 152 genes had reduced expression under in vivo conditions in nondiabetic and diabetic animals, respectively, compared with both planktonic conditions; 208 and 199 genes had lower expression in vivo compared to logarithmic phase cultures only; and 183 and 106 genes had lower expression in vivo compared to stationary phase cultures only. The largest group of genes differentially expressed in vegetations was genes of unknown function (hypothetical proteins). The next largest groups were genes involved in transcription, translation, and posttranslational modification; amino acid transport and metabolism; cell wall and membrane biogenesis; nucleotide metabolism and replication; carbohydrate transport and metabolism; and virulence or immune-evasion mechanisms (Figure 2). Numerous virulence-associated genes, such as toxins and proteases, were more highly expressed in endocardial vegetations than in planktonic cultures.

A selection of $S$. aureus genes differentially expressed in endocardial vegetations compared to planktonic growth conditions in vitro is presented in Table 2. Among the virulence-associated upregulated genes were the alpha-, delta-, and gamma-hemolysins and the bi-component leukocidins LukS and LukF, which were more highly expressed under in vivo conditions than in vitro conditions. Likewise, genes encoding the metalloprotease aureolysin, the serine proteases SplBCDE, and the staphylococcal secretory antigen SsaA were all upregulated in vivo. Staphylococcal enterotoxin B (seb) showed higher expression in vegetations and in stationary growth phase compared with $S$. aureus in logarithmic growth phase. Neither srtA (encoding sortase A) nor putP (proline permease) showed differential expression in vivo. The superoxide dismutase $\operatorname{sod} A$ was significantly downregulated in endocardial vegetations compared with both in vitro conditions.
The capsule synthesis operon (cap5A to cap5J) was more highly expressed in vegetations than in either planktonic growth phases, whereas the $d l t A B C D$ operon (encoding enzymes mediating D-alanylation of teichoic acids in the cell envelope) was downregulated in vivo compared with in vitro. Regarding the $S$. aureus ica locus that encodes poly-N-acetyl glucosamine, apparently COL does not synthesize this surface-associated polymer since it has a mutated icaC gene (SACOL2692). Most of the other ica genes were not differentially expressed in vivo and in vitro.

Among the staphylococcal surface proteins, clumping factor A (ClfA) and B (ClfB) genes were more highly expressed in vivo compared with logarithmic- or stationary growth-phase planktonic cultures, respectively. Fibronectin-binding protein A was significantly upregulated in the vegetations of nondiabetic rats. Genes encoding the LPXTG-anchored proteins SdrC (a betaneurexin-binding protein) and SasF (associated with resistance to linoleic acid) were upregulated in vivo compared with both in vitro conditions. Of note, expression of both spa (encoding protein A) and pls (encoding a surface-associated plasmin-sensitive protein) were significantly lower in vivo than in vitro.

Regarding iron acquisition, we observed high in vivo expression of the $s b n$ operon-encoding proteins required for the synthesis of the nonhydroxamate siderophore staphyloferrin B. SbnABDEGHI were significantly upregulated in vegetations from diabetic animals compared with logarithmic and stationary phase planktonic cultures. The same trend and magnitude of changes in expression were also observed in nondiabetic vegetations, but were not considered statistically significant. In addition, $\operatorname{sir} B$, part of the sir $A B C$ operon encoding transport of staphyloferrin B into the bacterial cell $[23,27]$, showed significant upregulation in nondiabetic rats with endocarditis. Some of the genes encoding the siderophore staphyloferrin A (SACOL2167, SACOL2169, and SACOL2170 [28]) were upregulated in endocardial vegetations (Table 2).

Several of the iron-regulated $S$. aureus genes were also involved in transport. Among the Isd genes that mediate heme uptake, only is $d D$ (a heme $\mathrm{ABC}$ transporter) was consistently upregulated in vivo and only versus logarithmic phase $S$. aureus. Other iron-regulated genes with significantly higher expression in vivo included the oligopeptide permease and norD genes of the opp $1 A B C D F n o r D$ operon [29]. Numerous genes encoding transporters were highly expressed by $S$. aureus in endocardial vegetations. The maltose transport (malEFK) genes were almost uniformly upregulated in vivo by staphylococci recovered from infected vegetations of nondiabetic and diabetic rats. Similarly, $k d p A B$ genes encoding a potassium-transporting ATPase were upregulated in diabetic vegetations compared to both in vitro growth conditions. Other upregulated 
Table 2 Selected genes that were differentially expressed in endocardial vegetations

\begin{tabular}{|c|c|c|c|c|c|c|}
\hline Gene & & $\begin{array}{l}\text { Nondiabetic versus } \\
\text { logarithmic phase }\end{array}$ & $\begin{array}{l}\text { Vegetation versus } \\
\text { stationary phase }\end{array}$ & $\begin{array}{l}\text { Diabetic versus } \\
\text { logarimthic phase }\end{array}$ & $\begin{array}{l}\text { Vegetation } \\
\text { versus } \\
\text { stationary }\end{array}$ & Gene product \\
\hline \multicolumn{7}{|c|}{ Virulence-associated genes } \\
\hline hla & SACOL1173 & 22.9 & ns & 17.5 & ns & alpha-hemolysin precursor \\
\hline hld & SACOL2022 & 38.5 & ns & 37.8 & ns & delta-hemolysin \\
\hline$h \lg A$ & SACOL2419 & 18.5 & 5.4 & 6.3 & 2.1 & gamma-hemolysin, component A \\
\hline$h \lg B$ & SACOL2421 & 11.8 & 2.7 & ns & ns & gamma hemolysin, component B \\
\hline$h \operatorname{lgC}$ & SACOL2422 & 16.5 & 2.4 & ns & ns & gamma hemolysin, component $C$ \\
\hline lukF & SACOL2004 & 11.1 & 18.7 & 4.9 & 8.1 & leukocidin F subunit \\
\hline lukS & SACOL2006 & 11.9 & 14.7 & 6.4 & 8.0 & leukocidin S subunit \\
\hline nuc & SACOL0860 & ns & ns & 2.9 & 7.8 & thermonuclease \\
\hline seb & SACOL0907 & 8.0 & ns & 4.1 & ns & staphylococcal enterotoxin B \\
\hline$s p / B$ & SACOL1868 & 10.7 & 5.7 & ns. & ns & serine protease \\
\hline sp/C & SACOL1867 & ns & ns & 3.4 & 2.5 & serine protease \\
\hline splD & SACOL1866 & ns & ns & 3.8 & 2.9 & serine protease \\
\hline splE & SACOL1865 & 28.4 & 11.6 & 16.9 & 7.5 & serine protease \\
\hline aur & SACOL2659 & 3.3 & 2.4 & 2.2 & ns & zinc metalloproteinase aureolysin \\
\hline$c l p B$ & SACOL0979 & ns & ns & 4.4 & 8.1 & ATP-dependent protease \\
\hline$s s a A$ & SACOL2581 & 5.7 & 13.1 & 2.6 & 5.1 & $\begin{array}{l}\text { staphylococcal secretory antigen; } \\
\text { staphyloxanthin biosynthesis protein }\end{array}$ \\
\hline sodA & SACOL1610 & -5.7 & -4.5 & -5.7 & -4.5 & superoxide dismutase \\
\hline \multicolumn{7}{|c|}{ Cell wall and capsule synthesis } \\
\hline cap5A & SACOL0136 & 8.5 & 2.8 & 8.8 & 3.0 & $\begin{array}{l}\text { capsular polysaccharide biosynthesis } \\
\text { protein }\end{array}$ \\
\hline cap5B & SACOL0137 & 7.3 & 2.6 & 7.4 & 2.6 & $\begin{array}{l}\text { capsular polysaccharide biosynthesis } \\
\text { protein }\end{array}$ \\
\hline cap5D & SACOL0139 & 6.3 & 2.2 & 7.4 & 3.8 & $\begin{array}{l}\text { capsular polysaccharide biosynthesis } \\
\text { protein }\end{array}$ \\
\hline cap5E & SACOL0140 & 13.4 & 10.2 & 9.1 & 6.8 & $\begin{array}{l}\text { capsular polysaccharide biosynthesis } \\
\text { protein }\end{array}$ \\
\hline cap5F & SACOL0141 & 5.3 & 3.6 & ns & ns & $\begin{array}{l}\text { capsular polysaccharide biosynthesis } \\
\text { protein }\end{array}$ \\
\hline cap5G & SACOL0142 & 4.3 & 2.5 & 6.6 & 4.0 & $\begin{array}{l}\text { capsular polysaccharide biosynthesis } \\
\text { protein }\end{array}$ \\
\hline cap5l & SACOL0144 & 3.3 & ns & 4.1 & 2.3 & $\begin{array}{l}\text { capsular polysaccharide biosynthesis } \\
\text { protein }\end{array}$ \\
\hline cap5J & SACOL0145 & ns & ns & 2.2 & 2.4 & $\begin{array}{l}\text { capsular polysaccharide biosynthesis } \\
\text { protein }\end{array}$ \\
\hline dlt $A$ & SACOL0935 & -8.5 & -2.9 & -6.2 & -2.1 & D-alanine-ligase subunit 1 \\
\hline$d l t B$ & SACOL0936 & -10.8 & -3.4 & -9.5 & -2.8 & $\begin{array}{l}\text { D-alanyl-lipoteichoic acid biosynthesis } \\
\text { protein }\end{array}$ \\
\hline ditc & SACOL0937 & -4.9 & ns & -4.9 & ns & D-alanine-ligase subunit 2 \\
\hline$d l t D$ & SACOL0938 & -13.5 & -3.5 & -7.4 & -2.0 & D-alanine transfer protein \\
\hline \multicolumn{7}{|c|}{ Surface proteins } \\
\hline clfA & SACOL0856 & 5.8 & ns & 5.6 & ns & clumping factor $\mathrm{A}$ \\
\hline clfB & SACOL2652 & ns & ns & ns & 3.1 & clumping factor $\mathrm{B}$ \\
\hline$f n b A$ & SACOL2511 & 3.4 & 2.7 & ns & ns & fibronectin-binding protein A \\
\hline sasF & SACOL2668 & 12.2 & 10.5 & 14.4 & 12.9 & $\begin{array}{l}\text { LPXTG cell wall surface anchor family } \\
\text { protein }\end{array}$ \\
\hline
\end{tabular}


Table 2 Selected genes that were differentially expressed in endocardial vegetations (Continued)

\begin{tabular}{llll}
\hline $\boldsymbol{s d r C}$ & SACOL0519 & 12.3 & 8.7 \\
pls & SACOL0050 & -2.3 & -3.3 \\
sasA & SACOL2676 & ns & -9.8 \\
& & & \\
spa & SACOL0095 & -6.3 & -4.9
\end{tabular}

\section{$-3.3$}

$-9.8$

$-4.9$

Iron uptake and iron-regulated genes

\begin{tabular}{|c|c|c|}
\hline$s b n A$ & SACOL0112 & ns \\
\hline$s b n B$ & SACOL0101 & ns \\
\hline$s b n D$ & SACOL0103 & ns \\
\hline sbnE & SACOL0104 & ns \\
\hline sbnG & SACOL0106 & ns \\
\hline$s b n H$ & SACOL0107 & ns \\
\hline$s b n l$ & SACOL0108 & ns \\
\hline $\operatorname{sirR}$ & SACOL0691 & 2.3 \\
\hline $\operatorname{sir} B$ & SACOL0098 & 2.9 \\
\hline & SACOL2167 & ns \\
\hline & SACOL2169 & 4.4 \\
\hline & SACOL2170 & ns \\
\hline
\end{tabular}

Transport

isdD SACOL1142 3.1

dapF SACOL2479 18.2

SACOL2478 9.2

SACOL2477 17.6

opp1A SACOL2476 18.1

opp1B SACOL2475 4.3

opp1C SACOL2474 15.9

opp1D SACOL2473 ns

opp1F SACOL2472 ns

norD SACOL2471 17.8

epig SACOL1871 2.4

epiE SACOL1872 4.2

epiF SACOL1873 5.5

malE SACOL0193 ns

malF SACOL0194 7.4

malK SACOL0192 14.7

opuD SACOL2176 2.0

tet38 SACOL0122 21.2

ulaA SACOL0400 12.9 ns

ns

ns

ns

ns

ns

ns

ns

ns

ns

ns

ns

ns

18.9

9.4

12.8

11.1

3.4

12.9

ns

ns

12.3

ns

ns

ns

ns

3.9

14.7

2.4

12.2

5.6

8.6

ns

2.2

$-5.7$

48.9

25.9

18.4

23.0

21.6

15.4

23.5

ns

ns

2.9

4.2

2.6

2.3

15.2

7.8

20.9

10.8

11.2

30.4

8.0

21.5

27.0

2.6

4.4

5.7

3.1

6.0

6.2

ns

13.1

7.3
Ser-Asp repeat protein

surface protein

LPXTG cell wall surface anchor family protein

immunoglobulin G-binding protein A precursor

siderophore biosynthesis protein siderophore biosynthesis protein siderophore biosynthesis protein siderophore biosynthesis protein siderophore biosynthesis protein siderophore biosynthesis protein siderophore biosynthesis protein iron-dependent repressor iron compound $A B C$ transporter, permease

iron complex transport substratebinding protein

aerobactin biosynthesis protein

major facilitator transporter

Heme ABC transporter

diaminopimelate epimerase family protein

conserved hypothetical protein conserved hypothetical protein peptide $A B C$ transporter peptide $A B C$ transporter, permease peptide $A B C$ transporter, permease peptide $A B C$ transporter ATP-binding protein

peptide $A B C$ transporter ATP-binding protein

transporter, putative

lantibiotic $A B C$ transporter protein lantibiotic $A B C$ transporter protein lantibiotic $A B C$ transporter protein maltose $A B C$ transporter, maltosebinding

maltose $A B C$ transporter, permease protein

maltose $\mathrm{ABC}$ transporter, ATP-binding protein

osmoprotectant transporter, BCCT family

tetracycline-resistance protein, putative

PTS system ascorbate-specific transporter 
Table 2 Selected genes that were differentially expressed in endocardial vegetations (Continued)

\begin{tabular}{|c|c|c|c|c|c|c|}
\hline uhpT & SACOL0200 & 125 & 29 & 78.1 & 18.1 & sugar phosphate antiporter \\
\hline$k d p A$ & SACOL2068 & ns & ns & 8.5 & 15.0 & $\begin{array}{l}\text { potassium-transporting ATPase, } \\
\text { C subunit }\end{array}$ \\
\hline$k d p B$ & SACOL2067 & ns & ns & 9.0 & 13.3 & $\begin{array}{l}\text { potassium-transporting P-type ATPase, } \\
\text { B unit }\end{array}$ \\
\hline \multirow[t]{2}{*}{ norB } & SACOL1475 & 25.1 & 27.5 & 16.1 & 17.3 & $\begin{array}{l}\text { drug transporter, quinolone-resistance } \\
\text { protein }\end{array}$ \\
\hline & SACOL1476 & 24.8 & 22.4 & 18.7 & 18.6 & $\begin{array}{l}\text { transmembrane amino acid } \\
\text { transporter }\end{array}$ \\
\hline ilvA & SACOL1477 & 34.0 & 25.0 & 28.7 & 22.7 & threonine dehydratase \\
\hline ald & SACOL1478 & 42.3 & 24.0 & 31.2 & 17.6 & alanine dehydrogenase \\
\hline \multirow[t]{2}{*}{ mntH } & SACOL1114 & -9.5 & -6.3 & -9.4 & -6.3 & $\mathrm{Mn} 2+/ \mathrm{Fe} 2+$ transporter \\
\hline & SACOL1115 & -3.9 & -4.0 & -4.3 & -4.4 & hypothetical protein \\
\hline mntC & SACOL0688 & 3.7 & -5.8 & 3.5 & -6.3 & $\begin{array}{l}\text { ABC transporter substrate-binding } \\
\text { protein }\end{array}$ \\
\hline$m n t B$ & SACOL0689 & 4.1 & -5.7 & 4.5 & -4.7 & $A B C$ transporter permease \\
\hline \multirow[t]{5}{*}{$m n t A$} & SACOL0690 & 8.5 & -2.7 & 5.6 & -4.4 & ABC transporter ATP-binding protein \\
\hline & SACOL0157 & -11.4 & -12.0 & -12.9 & -12.8 & conserved hypothetical protein \\
\hline & SACOL0158 & -6.8 & -15.2 & -6.1 & -13.4 & ABC transporter, ATP-binding protein \\
\hline & SACOL0159 & -6.9 & -8.2 & -5.0 & -6.1 & $A B C$ transporter, permease protein \\
\hline & SACOL0160 & -4.9 & -7.1 & -5.5 & -7.9 & conserved hypothetical protein \\
\hline \multicolumn{7}{|c|}{ Metabolism } \\
\hline adhE & SACOL0135 & 22.9 & 22.3 & 30.9 & 31.1 & $\begin{array}{l}\text { alcohol dehydrogenase, } \\
\text { iron-containing }\end{array}$ \\
\hline ald & SACOL1478 & 42.3 & 24.0 & 31.2 & 17.6 & alanine dehydrogenase \\
\hline $\operatorname{arcB1}$ & SACOL1181 & ns & ns & 2.2 & 2.5 & ornithine carbamoyltransferase \\
\hline $\operatorname{arcC}$ & SACOL1182 & 21.8 & 15.3 & 12.9 & 9.9 & carbamate kinase \\
\hline $\operatorname{arcD}$ & SACOL1183 & 8.7 & 5.9 & 6.8 & 4.8 & arginine/ornithine antiporter \\
\hline $\operatorname{arcA}$ & SACOL2657 & 12.4 & 12.2 & 8.4 & 8.5 & arginine deiminase \\
\hline $\operatorname{arcB2}$ & SACOL2656 & 6.4 & 7.6 & 4.6 & 5.3 & ornithine carbamoyltransferase \\
\hline $\operatorname{arcD}$ & SACOL2655 & 30.1 & 43.5 & 27.6 & 43.1 & arginine/ornithine antiporter \\
\hline $\arg G$ & SACOL0963 & ns & ns & 3.4 & 6.4 & argininosuccinate synthase \\
\hline $\operatorname{argH}$ & SACOL0964 & ns & ns & 5.4 & 13.3 & argininosuccinate lyase \\
\hline $\operatorname{deo} B$ & SACOL0124 & 4.0 & 2.2 & 4.4 & 2.3 & phosphopentomutase \\
\hline $\operatorname{deo} D$ & SACOL0121 & 7.1 & 7.8 & 8.9 & 10.0 & purine nucleoside phosphorylase \\
\hline$g / t A$ & SACOL1742 & 6.9 & -6.7 & 4.8 & -9.4 & citrate synthase \\
\hline gntK & SACOL2515 & 6.9 & 4.9 & ns & ns & gluconokinase \\
\hline ilvA & SACOL1477 & 34.0 & 25.0 & 28.7 & 22.7 & threonine dehydratase \\
\hline nirB & SACOL2398 & 21.8 & 19.6 & 12.8 & 11.9 & $\begin{array}{l}\text { nitrite reductase }[N A D(P) H] \text {, } \\
\text { large subunit }\end{array}$ \\
\hline nirD & SACOL2397 & 8.1 & 6.1 & 4.7 & 3.9 & $\begin{array}{l}\text { nitrite reductase }[\mathrm{NAD}(\mathrm{P}) \mathrm{H}] \text {, } \\
\text { small subunit }\end{array}$ \\
\hline pflA & SACOL0205 & 94.7 & 125.7 & 116.5 & 157.6 & $\begin{array}{l}\text { pyruvate formate-lyase-activating } \\
\text { enzyme }\end{array}$ \\
\hline$p f \mid B$ & SACOL0204 & 44.7 & 46.9 & 59.9 & 65.6 & formate acetyltransferase \\
\hline \multirow[t]{3}{*}{ rbsK } & SACOL0253 & 6.9 & 2.5 & 4.9 & ns. & ribokinase \\
\hline & SACOL2396 & 19.0 & 14.3 & 7.4 & 6.1 & uroporphyrin-III C-methyl transferase \\
\hline & SACOL1476 & 24.8 & 22.4 & 18.7 & 18.6 & amino acid permease \\
\hline
\end{tabular}


Table 2 Selected genes that were differentially expressed in endocardial vegetations (Continued)

\begin{tabular}{|c|c|c|c|c|c|c|}
\hline \multicolumn{7}{|c|}{ Regulators } \\
\hline $\operatorname{agrA}$ & SACOL2026 & ns & ns & 4.8 & ns & accessory gene regulator protein $A$ \\
\hline $\operatorname{agrC}$ & SACOL2025 & -2.6 & -3.3 & 4.5 & -2.2 & accessory gene regulator protein $C$ \\
\hline $\operatorname{agrD}$ & SACOL2024 & 2.3 & -4.0 & 5.2 & ns & accessory gene regulator protein $\mathrm{D}$ \\
\hline gntR & SACOL2516 & 5.0 & 4.1 & ns & ns & $\begin{array}{l}\text { gluconate operon transcriptional } \\
\text { repressor }\end{array}$ \\
\hline purR & SACOL0539 & ns & 2.3 & ns & ns & pur operon repressor \\
\hline$r s b V$ & SACOL2056 & ns & 3.6 & ns & 3.7 & anti-anti-sigma factor RsbV \\
\hline$r s b W$ & SACOL2055 & ns & 2.7 & ns & 3.0 & anti-sigma B factor \\
\hline sarA & SACOL0672 & ns & 2.5 & ns & 2.1 & transcriptional regulator \\
\hline sarS & SACOL0096 & -14.7 & -7.2 & -8.7 & -4.2 & transcriptional regulator \\
\hline $\operatorname{sig} B$ & SACOL2054 & ns & ns & ns & 2.1 & alternative sigma factor \\
\hline fur & SACOL1541 & ns & ns & -2.1 & -3.1 & transcriptional regulator, Fur family \\
\hline $\operatorname{araC}$ & SACOL2378 & -3.6 & -2.7 & ns & ns & transcriptional regulator, AraC family \\
\hline tetR & SACOL2374 & ns & ns & -2.0 & -2.4 & transcriptional regulator, TetR family \\
\hline vraR & SACOL1942 & -4.8 & -3.2 & -3.7 & -2.5 & DNA-binding response regulator \\
\hline vras & SACOL1943 & -4.3 & -2.8 & -3.3 & -2.2 & sensor histidine kinase \\
\hline
\end{tabular}

ns, difference not significant.

transporters include epiGEF, involved in lantibiotic transport, and tet38 and nor $B$, mediating drug resistance. Of note, $m n t H\left(\mathrm{a} \mathrm{Mn}{ }^{2+} / \mathrm{Fe}^{2+}\right.$ transporter) was downregulated in vivo compared with both planktonic conditions, whereas the $m n t A B C$ operon (involved in $\mathrm{Mn}^{2+}$ uptake [30]) was upregulated compared with logarithmic phase $S$. aureus and downregulated compared with stationary phase cells. A large uncharacterized transporter operon (SACOL24712479) was upregulated in vivo, whereas the SACOL0157 to SACOL0160 operon had significantly lower expression levels in vegetations than in planktonic cultures.

Genes associated with metabolic pathways and more highly expressed in vegetations were numerous and included an alcohol dehydrogenase $(a d h E)$, nitrite reductase (nirBD), and genes implicated in arginine (argGH and two arc operons) and pyruvate (pflAB) metabolism.

Transcription of a few staphylococcal regulatory genes was enhanced in vivo. The transcriptional regulator GntR showed higher expression in vivo in nondiabetic rats. By contrast, genes encoding the staphylococcal accessory regulator SarS, the iron-regulated repressor Fur, the regulators VraR and VraS, and the transcriptional regulator AraC had lower expression in vivo than in vitro (Table 2). The agr locus did not show consistent changes in vivo and in vitro (Table 2), although in diabetic rats the locus was upregulated compared with in vitro logarithmic phase cultures.

\section{Confirmation of upregulated genes in endocardial vegetations by real-time PCR}

We used quantitative PCR to confirm differential expression of selected genes in vivo. Genes were selected based on upregulation in microarray analysis, being a potential virulence factor, and not having been implicated in the pathogenesis of endocarditis previously. In vitro or in vivo expression of $s b n C, s d r C$, and $s p l B$ was thus quantified using the LightCycler real-time PCR system. Although the magnitude of the differences in gene expression varied, we observed an overall good correlation between gene expression measured by microarray and LightCycler. All three genes tested showed a trend towards higher gene expression levels in vivo, but only $s p l B$ showed significantly higher gene expression in endocardial vegetations compared with both planktonic growth phases (60.4-fold upregulation versus logarithmic growth phase, $P<0.01$; and 8.6 -fold versus stationary growth phase, $P=0.03$ ). Expression levels of $s b n C$ and $s d r C$ in endocardial vegetations were significantly higher compared with logarithmic growth phase $S$. aureus (502.3-fold for $\operatorname{sbn} C, P<0.01$; and 25.1-fold for $s d r C$, $P<0.01)$.

\section{Role of selected genes in the pathogenesis of S. aureus endocarditis}

To assess the contribution of selected genes preferentially expressed in vivo to the pathogenesis of S. aureus endocarditis, we performed virulence studies in the nondiabetic rat endocarditis model. We chose genes that had not previously been implicated as important in endocarditis - the $s b n$ locus (encoding staphyloferrin B) and the $s d r C D E$ locus (involved in fibrinogen-mediated $S$. aureus adherence to platelets under in vitro shear flow conditions [31]). Rats infected with Newman $\Delta s b n E$ 


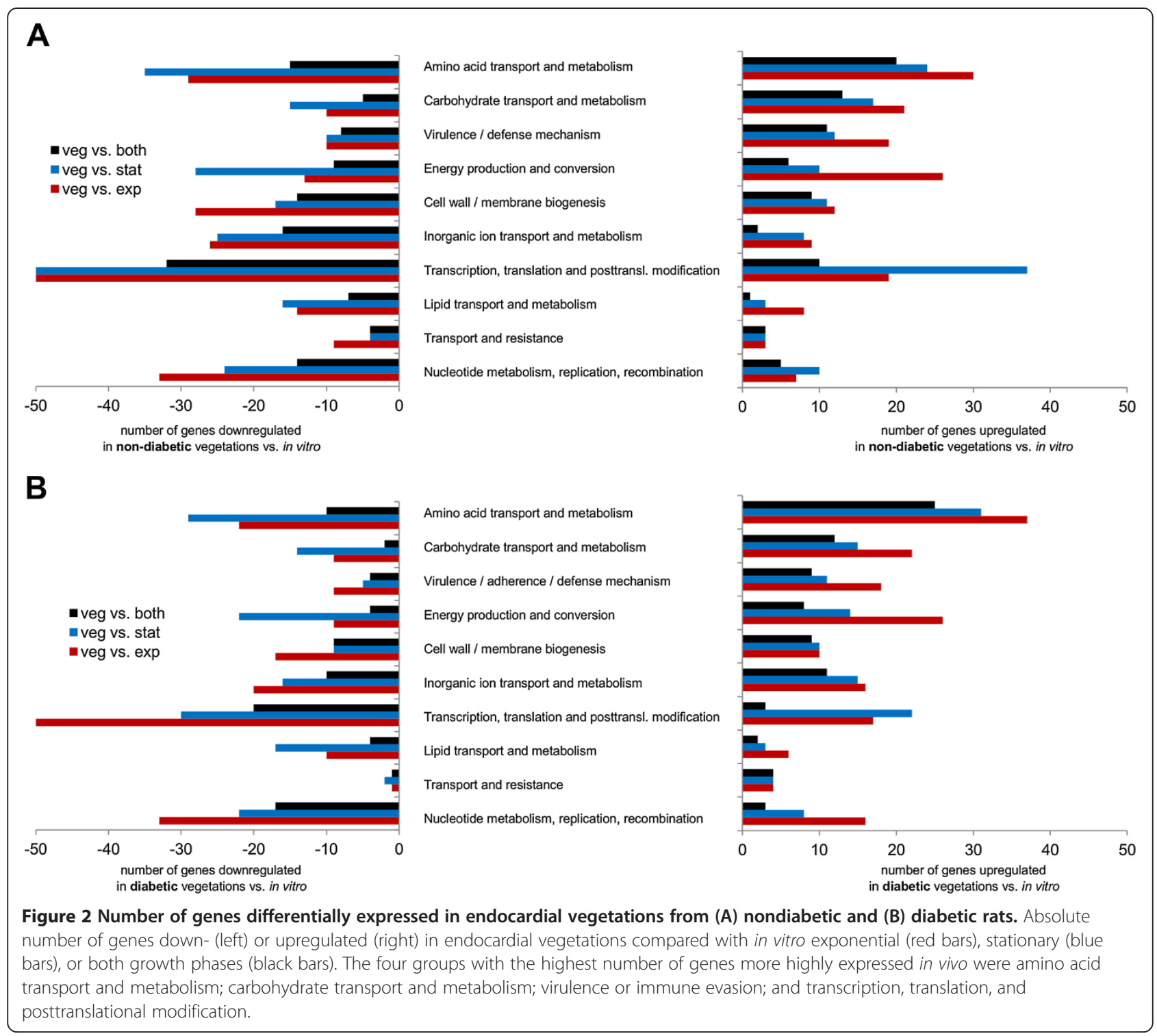

survived longer than rats infected with the parental isolate (Figure 3A; $P=0.047$, log-rank analysis), and they had lower bacteremia levels at all time points, although the differences reached significance only on day $2(P=$ 0.039; Figure 3B). Likewise, rats infected with strain Newman experienced greater weight loss $(P=0.002)$ than rats infected with the $s b n E$ mutant (Figure $3 C$ ). No significant differences were observed in the bacterial burden in kidneys (Figure 3D) or vegetations (Figure 3E) from rats infected with Newman or the $\Delta s b n E$ mutant. By contrast, rats infected with strain Newman or the $\triangle s d r C D E$ mutant had similar survival times (not shown), bacteremia levels (Additional file 1: Figure S1A), and weight loss (Additional file 1: Figure S1B). Likewise, the bacterial burdens in the kidneys (Additional file 1: Figure S1C) and endocardial vegetations (Additional file 1: Figure S1D) were comparable for wild-type and $\triangle s d r C D E$ strains.

\section{Discussion}

Patients with diabetes have a higher risk of staphylococcal infections than those without diabetes, and patients with diabetes who develop $S$. aureus infective endocarditis are likely to experience a poor outcome $[2,5]$. We have demonstrated in an animal model of $S$. aureus endocarditis that diabetes is associated with a more severe disease course, as reflected by higher levels of bacteremia and larger endocardial vegetations. We used the vegetations recovered from infected rats on infection day 3 to investigate the in vivo transcriptome of $S$. aureus in the setting of an acute infection. This time point allowed maximal recovery of organisms multiplying within the host and allowed us to recover sufficient bacterial RNA for analysis.

Characterization of gene regulation and gene expression under in vivo conditions is a prerequisite for alternative 

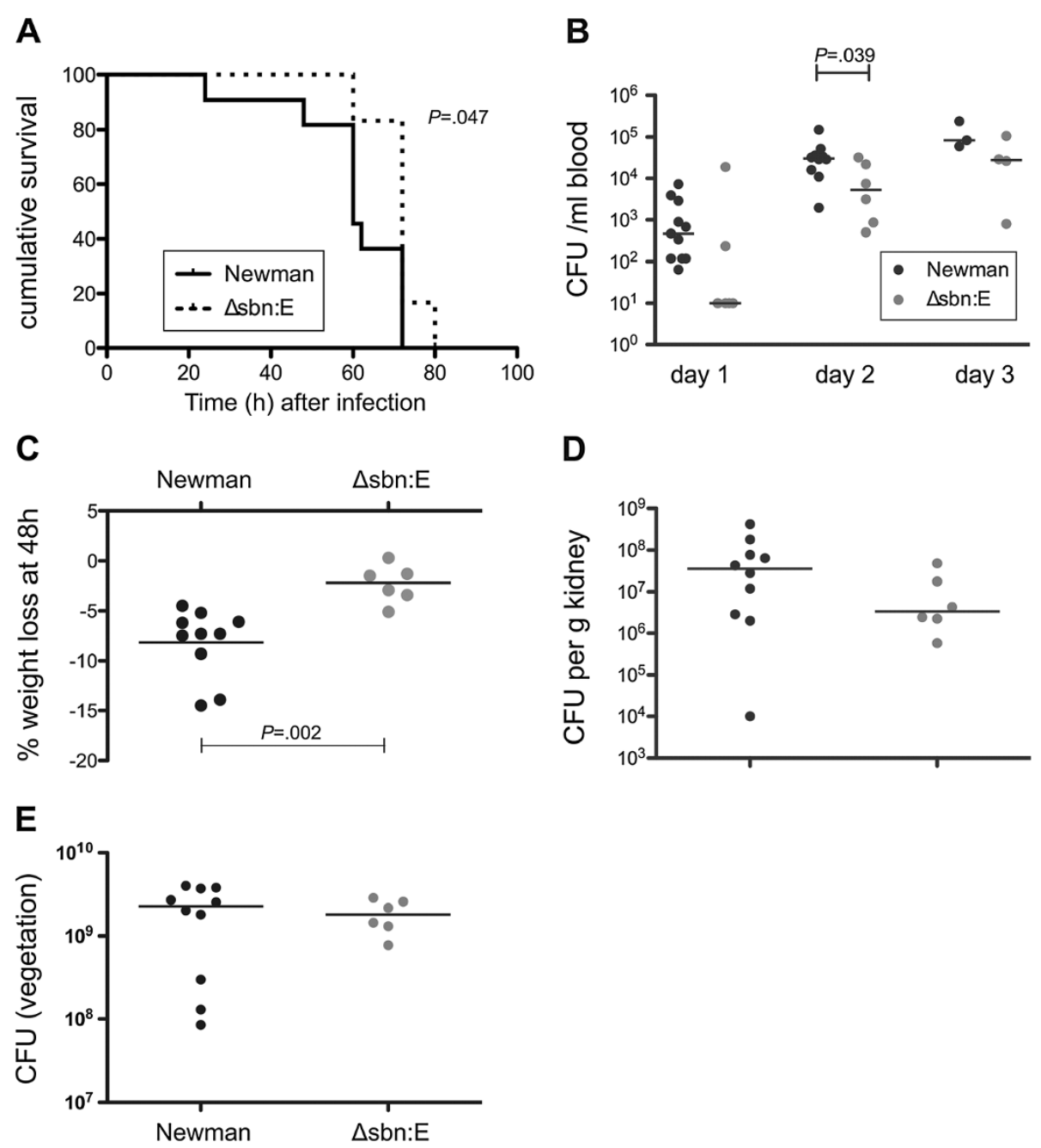

Figure 3 Comparative virulence of strain Newman and its isogenic sbnE deletion mutant. (A) Compared to rats infected with strain Newman, rats infected with the sbnE mutant (defective in the synthesis of the siderophore staphyloferrin $\mathbf{B}$ lived significantly longer than rats infected with the parental strain, (B) had significantly lower levels of bacteremia on day 2, and (C) lost significantly less weight $48 \mathrm{~h}$ after bacterial inoculation. (D) Bacterial burdens in the kidneys and (E) vegetations were not significantly different between wild-type and mutant strain.

treatment approaches, including the development of new drug targets and vaccination strategies. The S. aureus transcriptome under in vivo conditions has not been well characterized. Global S. aureus gene expression in vitro has been investigated after in vitro exposure to microbicides [32], in response to mild acid [33], during growth in biofilm [34], in blood [35], and after phagocytosis [36]. Changes in S. aureus gene expression during early adaptation to the mouse lung have been described [19], and Date et al. recently reported global $S$. aureus gene expression in human abscesses and infected murine kidneys [20]. Our study is the first description of the S. aureus transcriptome during an established endocardial infection. We used rich medium (TSB) as an in vitro comparator condition, although minimal medium such as Roswell Park Memorial Institute medium may better reflect iron-limited conditions in vivo. The choice of TSB as the in vitro comparator medium may explain some of the differences in gene expression reported (for example, iron-rich medium versus iron-depleted in vivo conditions). However, one of the aims of our study was to compare the gene expression pattern observed in endocarditis vegetations to gene expression found during growth under standard laboratory conditions. Our approach thus ensures comparability to previously published in vitro data (including previous microarray data, for example [26,36-38]). It also highlights the important contribution of in vivo conditions (for example, iron starvation) to $S$. aureus gene expression during an infection. An additional limitation of our study is the lack of a glucose-supplemented in vitro control arm. However, the fact that we did not observe significant differences in $S$. aureus virulence gene expression between nondiabetic and diabetic rats makes this additional control less important. 
S. aureus COL is a well-defined and sequenced MRSA strain, which we used for the experiments with diabetic versus nondiabetic rats and the microarray analyses. Moreover, all gene expression studies and subsequent analyses were performed with strain COL. A related methicillin-sensitive $S$. aureus strain (Newman [39]) was used for the single gene knockout studies because of the availability of relevant mutant strains. Mutations in strains Newman and COL have been described [40-42], and both strains are members of clonal complex 8 and readily produce endocarditis in rats.

We observed that more than 100 genes were upregulated in endocardial vegetations compared with in vitro cultures. However, the number of genes significantly downregulated in vivo was approximately two-fold higher than the number of genes upregulated in vivo. This may be because in vivo S. aureus gene expression was analyzed from vegetations three days after bacterial challenge. Date et al. [20] reported similar gene expression patterns in human abscesses and infected murine kidneys for some $S$. aureus genes, such as the serine proteases spl, gamma-hemolysin, and the oppl operon. Other genes with higher expression levels in abscesses, such as the isd genes, however, were not differentially expressed in endocardial vegetations in our study.

A majority of the genes that were differentially expressed in endocardial vegetations have not yet been assigned a function or are classified as hypothetical proteins. ClfA is a critical virulence factor in $S$. aureus endocarditis [10] and clfA transcript levels have been reported to increase after the late logarithmic growth phase in vitro [43]. In our study, clfA was upregulated in vivo versus logarithmic growth phase cells, whereas fibronectin-binding protein A was found to be significantly upregulated in nondiabetic vegetations only. Both are likely to be critical for initiation of infection, as has been described in previous studies [44,45]. Although acapsular strains provoke endocarditis at lower inocula than encapsulated isolates [46], S. aureus recovered from vegetations produce large quantities of capsular polysaccharides [12], consistent with our observation that the cap5 genes were upregulated in established vegetations. Capsule production enhances bacteremia in vivo and renders the bacterium resistant to uptake and killing by neutrophils [47]. Moreover, active and/or passive immunization strategies targeting capsular polysaccharides were able to protect rodents against $S$. aureus bacteremia [48] and endocarditis [25]. In contrast to the cap5 genes, the $d l t$ operon was downregulated in endocardial vegetations. The $d l t$ genes encode proteins mediating D-alanylation of lipoteichoic and wall teichoic acids, and transcription of the dlt genes is repressed in the presence of cations such as magnesium salt [49].
Higher $d l t$ expression has been associated with daptomycin resistance [50], and the observation that dlt is downregulated in endocardial vegetations could thus support clinical and preclinical data on the use of daptomycin in staphylococcal endocarditis [51,52].

Other virulence factors upregulated in vivo include exotoxins (hemolysins and leukotoxins) and proteases. The serine protease genes $s p l A$ to $s p l E$ are located on a pathogenicity island [39], and these proteases play a role in the degradation and inactivation of antibacterial peptides [53]. Both Spl proteases and aureolysin (aur) are associated with detachment of S. aureus from established biofilms [54] and may promote bacteremia by dispersing staphylococci from endocardial vegetations. Exotoxins upregulated in endocardial vegetations include two-component poreforming cytolysins such as gamma-hemolysin and LukFS that are able to lyse erythrocytes and leukocytes [55]. Other factors previously implicated in the pathogenesis of endocarditis, such as SrtA [15] and PutP [16], were not differentially expressed in endocardial vegetations compared with planktonic conditions.

To acquire iron from the host organism, S. aureus synthesizes two major nonhydroxamate siderophores (staphyloferrin A and staphyloferrin B $[28,56])$, as well as proteins that mediate the import and utilization of iron bound to heme or transferrin [57]. Although heme was identified as a preferred iron source for S. aureus [57], we found that genes for neither the iron surface determinant (isd) nor the heme transport system ( $h t s$ ) were significantly upregulated in endocardial vegetations (with the exception of isdD compared with exponential phase cultures). By contrast, the staphyloferrin $\mathrm{B}$ synthesis operon ( $\operatorname{sbn} A$ to $s b n I)$ was preferentially upregulated in vivo. There was also a trend towards higher expression in vivo of the fhuCBG operon encoding an $\mathrm{ABC}$ transporter for iron(III)-hydroxamates [58]. However, fhuD1 and fhuD2, encoding iron(III)hydroxamate-binding lipoproteins, were not upregulated in endocarditis (not shown). The observed differences in iron uptake systems may in part be attributable to different experimental conditions and the animal models employed (for example [59]).

Dale et al. [23] constructed a Newman mutant $(\Delta s b n E)$ deficient in staphyloferrin B synthesis, and introduction of $s b n E$ on a plasmid complemented the inability of the mutant to produce the siderophore under iron-limiting conditions. The Newman $\triangle s b n E$ mutant was compromised in the $S$. aureus renal abscess model [23]. This mutant was attenuated in the endocarditis model because rats inoculated with the mutant showed lower bacteremia levels, reduced weight loss, and increased survival compared with animals challenged with the parental strain. Although the reduction in virulence was modest, this can likely be attributed to the multitude of 
virulence factors involved in the pathogenesis of staphylococcal endocarditis. Thus, staphyloferrin B appears to promote staphylococcal virulence in abscesses and endocarditis.

Genes encoding multiple transporters were highly expressed in endocardial vegetations, including amino acid permeases, the lantibiotic transporter proteins EpiEFG, a maltose transporter, a potassium ATPase, the norD-opp1 operon, and genes associated with drug resistance, such as tet 38 and nor $B$. NorB promoted bacterial survival in a subcutaneous abscess model [17], and has broad substrate specificity. Upregulation of nor $B$ under conditions of low $\mathrm{pH}$ or reduced aeration has been reported [60]. Similarly, the efflux pump transporter NorD is iron-regulated and highly expressed in staphylococcal abscesses [29]. NorD is part of an operon with five upstream oligopeptide permease genes (opp $1 A B C D F)$, and all were significantly upregulated in endocardial vegetations. NorB and NorD efflux pumps may eliminate toxic metabolites or antibacterial factors produced by the host in vivo, although their substrates remain to be defined.

Among the surface molecules with higher expression in endocardial vegetations were the LPXTG-containing protein SasF, and the $\beta$-neurexin-binding protein SdrC. Genes within the $s d r$ region $(s d r C D E)$ have been reported to be differentially transcribed [61], and $s d r$ genes other than $s d r C$ were not upregulated in endocardial vegetations. $\mathrm{SdrC}$ could mediate initial contact with host cells or cell adhesion molecules, such as $\beta$-neurexin [62], although our experimental endocarditis data indicate that it was not critical for the establishment of endocarditis. SdrC may play a role in complications of infectious endocarditis, such as metastatic seeding to neuronal tissues.

The largest group of genes differentially expressed in vivo were involved in amino acid transport and metabolism. The chromosomal arginine deiminase pathway $(\operatorname{arc} A B C D)$ was strongly upregulated in endocardial vegetations. Arginine metabolism may serve to counter acidification or as an energy source under anaerobic conditions [63]. The latter is supported by the fact that nitrate reductase (NirBD) and pyruvate formate lyase (PflAB [64]) were also upregulated in endocardial vegetations. Expression of the superoxide dismutase gene $\operatorname{sod} A$, which is induced under microaerophilic conditions [65], was reduced in endocardial vegetations. Although staphylococcal vegetations grow in the oxygen-rich bloodstream at the aortic valve, the microenvironment within the vegetation may be oxygen-starved. Of note, we also observed differential gene expression of several gene clusters with yet unknown function (for example, upregulation of SACOL2477 to SACOL2479 and downregulation of SACOL0157 to SACOL0160 in endocardial vegetations). Their role in staphylococcal infections and contribution to the pathogenesis of endocarditis in particular remains to be determined.

$S$. aureus gene expression is controlled by a complex network of regulatory proteins. In a previous study, expression of $S$. aureus agr in rabbit endocardial vegetations was shown to increase over time and to correlate with bacterial densities in vegetations [66]. We observed that the agr operon was only consistently upregulated in endocardial vegetations, compared to cultures harvested from the logarithmic growth phase, in diabetic rats. The $S$. aureus fur regulator, which represses genes involved in iron acquisition, cytolysins, and immunomodulatory proteins [67], also had lower expression in endocardial vegetations than in vitro, as did the transcriptional regulator sarS. Differential expression of other regulatory genes included downregulation of vraSR (involved in resistance to cell wall active antibiotics and antimicrobial peptides [68]) and the araC family regulator (linking environmental chemical signals and virulence factors [69]), and upregulation of the gluconate repressor operon $g n t R$. The saeS gene was significantly downregulated in vivo in the vegetations of diabetic rats.

With regard to genes differentially expressed in endocardial vegetations from diabetic and nondiabetic rats, we found 61 genes with higher expression levels in vegetations from diabetic animals. Although bacterial densities in the vegetations from both groups were similar (not shown), vegetations from diabetic animals were significantly larger and contained more bacteria than their nondiabetic counterparts. The composition or size of these vegetations may have an influence on staphylococcal gene expression in endocarditis. Of note, several of the differentially expressed genes with high upregulation (argG, $\operatorname{argH}, g l y S$, ureC) were previously reported to be upregulated in biofilms versus planktonic cultures [26]. Other genes found to be upregulated in diabetic vegetations ( $\operatorname{gapA}$, hemX, $n r d F)$ were demonstrated to be under the control of glucose and CcpA [70]. In summary, we cannot exclude that differences in gene expression observed between diabetic and nondiabetic rats with endocarditis reflect differences in the size of the vegetations involved (possibly attributable to an altered innate immune response in diabetic hosts). However, there is also evidence that $S$. aureus may sense (and possibly benefit from) increased glucose levels in hosts with diabetes mellitus.

\section{Conclusions}

We have demonstrated that diabetes mellitus leads to higher bacterial burdens in an experimental model of $S$. aureus endocarditis. Gene expression patterns in endocardial vegetations differed from those observed during in vitro growth, with overall downregulation of transcription. Endocarditis promoted higher expression of genes 
encoding toxins, surface proteins, and enzymes involved in capsule biosynthesis, iron homeostasis, and glucose and amino acid metabolism. Our findings indicate that gene expression of the staphyloferrin B operon is upregulated in endocarditis, and that production of this siderophore promoted staphylococcal virulence in this infection model. These results may form a basis for future analyses of specific genes, regulators, and pathways that are critical in endocarditis and other infections. Our findings may thus contribute to a better understanding of $S$. aureus pathogenesis in vivo and lead to alternative approaches in prevention or treatment of staphylococcal endocarditis.

\section{Additional file}

Additional file 1: Figure S1. Comparative virulence of strain Newman and its isogenic sdrCDE deletion mutant. (A) Infection with the mutant strain led to comparable levels of bacteremia, (B) weight loss at $48 \mathrm{~h}$, (C) bacterial burden in the kidneys and (D) endocardial vegetations compared to infection with the parental strain. Table S1. Primers used for real-time PCR.

\section{Competing interests}

The authors declare that they have no competing interests.

\section{Authors' contributions}

$\mathrm{FH}$ and $\mathrm{JCL}$ designed the experiments; CR and PMD designed microarray experiments. All animal experiments were performed by FH and JCL; RNA isolation and quantitative PCR experiments were performed by $\mathrm{FH} ; \mathrm{CR}$ and PMD performed and analyzed the microarray experiments. All other data were analyzed by FH, BS and JCL. FH and JCL wrote the manuscript, and BS critically reviewed it. All authors read and approved the final manuscript.

\section{Acknowledgments}

This work was supported by the German Academy of Sciences Leopoldina (grant numbers BMBF-LPD 9901/8-157 and LPDR 2009-2 to FH) and by the National Institutes of Health (grant numbers R01 Al29040 and R01 Al088754 to $\mathrm{JCL}$ ). The content is solely the responsibility of the authors and does not necessarily represent the official views of the National Institute of Allergy and Infectious Diseases or the National Institutes of Health. Support was also provided by University of Rochester research funds (PMD). The funders had no role in the study design, data collection and analysis, decision to publish, or preparation of the manuscript. We thank Irina Fink for excellent technical assistance. The authors gratefully acknowledge Drs Timothy Foster and David Heinrichs for providing the S. aureus sdrCDE and sbnE mutants, respectively.

\section{Author details}

${ }^{1}$ Channing Laboratory, Department of Medicine, Brigham and Women's Hospital and Harvard Medical School, Boston, MA 02115, USA. ²Department of Internal Medicine I, University Hospital Regensburg, Franz-Josef-Strauss Allee 11, Regensburg 93049, Germany. ${ }^{3}$ Department of Microbiology and Immunology, University of Rochester, Rochester, NY 14642, USA.

\section{Received: 1 July 2014 Accepted: 20 October 2014}

Published online: 03 November 2014

\section{References}

1. Federspiel JJ, Stearns SC, Peppercorn AF, Chu VH, Fowler VG Jr: Increasing US rates of endocarditis with Staphylococcus aureus: 1999-2008. Arch Intern Med 2012, 172:363-365.

2. Sy RW, Kritharides L: Health care exposure and age in infective endocarditis: results of a contemporary population-based profile of 1536 patients in Australia. Eur Heart J 2010, 31:1890-1897.

3. Murdoch DR, Corey GR, Hoen B, Miro JM, Fowler VG Jr, Bayer AS, Karchmer AW, Olaison L, Pappas PA, Moreillon P, Chambers ST, Chu VH, Falco V, Holland DJ, Jones P, Klein JL, Raymond NJ, Read KM, Tripodi MF, Utili R,
Wang A, Woods CW, Cabell CH: Clinical presentation, etiology, and outcome of infective endocarditis in the 21st century: the International Collaboration on Endocarditis-Prospective Cohort Study. Arch Intern Med 2009, 169:463-473.

4. Walpot J, Blok W, van Zwienen J, Klazen C, Amsel B: Incidence and complication rate of infective endocarditis in the Dutch region of Walcheren: a 3-year retrospective study. Acta Cardiol 2006, 61:175-181.

5. Fowler VG Jr, Miro JM, Hoen B, Cabell CH, Abrutyn E, Rubinstein E, Corey GR, Spelman D, Bradley SF, Barsic B, Pappas PA, Anstrom KJ, Wray D, Fortes CQ, Anguera I, Athan E, Jones P, van der Meer JT, Elliott TS, Levine DP, Bayer AS: Staphylococcus aureus endocarditis: a consequence of medical progress. JAMA 2005, 293:3012-3021.

6. Kourany WM, Miro JM, Moreno A, Corey GR, Pappas PA, Abrutyn E, Hoen B, Habib G, Fowler VG Jr, Sexton DJ, Olaison L, Cabell CH, ICE MD Investigators: Influence of diabetes mellitus on the clinical manifestations and prognosis of infective endocarditis: a report from the International Collaboration on Endocarditis-Merged Database. Scand J Infect Dis 2006 38:613-619.

7. Delahaye F, Alla F, Beguinot I, Bruneval P, Doco-Lecompte T, Lacassin F, Selton-Suty C, Vandenesch F, Vernet V, Hoen B: In-hospital mortality of infective endocarditis: prognostic factors and evolution over an 8-year period. Scand J Infect Dis 2007, 39:849-857.

8. Rich J, Lee JC: The pathogenesis of Staphylococcus aureus infection in the diabetic NOD mouse. Diabetes 2005, 54:2904-2910.

9. Que YA, Haefliger JA, Piroth L, Francois P, Widmer E, Entenza JM, Sinha B, Herrmann M, Francioli P, Vaudaux P, Moreillon P: Fibrinogen and fibronectin binding cooperate for valve infection and invasion in Staphylococcus aureus experimental endocarditis. J Exp Med 2005, 201:1627-1635.

10. Moreillon P, Entenza JM, Francioli P, McDevitt D, Foster TJ, Francois P, Vaudaux P: Role of Staphylococcus aureus coagulase and clumping factor in pathogenesis of experimental endocarditis. Infect Immun 1995, 63:4738-4743.

11. Sullam PM, Bayer AS, Foss WM, Cheung AL: Diminished platelet binding in vitro by Staphylococcus aureus is associated with reduced virulence in a rabbit model of infective endocarditis. Infect Immun 1996, 64:4915-4921.

12. Lee JC, Takeda S, Livolsi PJ, Paoletti LC: Effects of in vitro and in vivo growth conditions on expression of type 8 capsular polysaccharide by Staphylococcus aureus. Infect Immun 1993, 61:1853-1858.

13. Cheung AL, Yeaman MR, Sullam PM, Witt MD, Bayer AS: Role of the sar locus of Staphylococcus aureus in induction of endocarditis in rabbits. Infect Immun 1994, 62:1719-1725.

14. Bayer AS, Ramos MD, Menzies BE, Yeaman MR, Shen AJ, Cheung AL: Hyperproduction of alpha-toxin by Staphylococcus aureus results in paradoxically reduced virulence in experimental endocarditis: a host defense role for platelet microbicidal proteins. Infect Immun 1997, 65:4652-4660.

15. Weiss WJ, Lenoy E, Murphy T, Tardio L, Burgio P, Projan SJ, Schneewind O, Alksne L: Effect of srtA and srtB gene expression on the virulence of Staphylococcus aureus in animal models of infection. J Antimicrob Chemother 2004, 53:480-486.

16. Bayer AS, Coulter SN, Stover CK, Schwan WR: Impact of the high-affinity proline permease gene (putP) on the virulence of Staphylococcus aureus in experimental endocarditis. Infect Immun 1999, 67:740-744.

17. Ding $Y$, Onodera $Y$, Lee JC, Hooper DC: NorB, an efflux pump in Staphylococcus aureus strain MW2, contributes to bacterial fitness in abscesses. J Bacteriol 2008, 190:7123-7129.

18. Goerke C, Fluckiger U, Steinhuber A, Bisanzio V, Ulrich M, Bischoff M, Patti JM, Wolz C: Role of Staphylococcus aureus global regulators sae and sigmaB in virulence gene expression during device-related infection. Infect Immun 2005, 73:3415-3421.

19. Chaffin DO, Taylor D, Skerrett SJ, Rubens CE: Changes in the Staphylococcus aureus transcriptome during early adaptation to the lung. PLoS One 2012, 7:e41329.

20. Date SV, Modrusan Z, Lawrence M, Morisaki JH, Toy K, Shah IM, Kim J, Park S, Xu M, Basuino L, Chan L, Zeitschel D, Chambers HF, Tan M-W, Brown EJ, Diep BA, Hazenbos WLW: Global gene expression of methicillin-resistant Staphylococcus aureus USA300 during human and mouse infection. J Infect Dis 2014, 209:1542-1550.

21. Pragman AA, Schlievert PM: Virulence regulation in Staphylococcus aureus: the need for in vivo analysis of virulence factor regulation. FEMS Immunol Med Microbiol 2004, 42:147-154. 
22. O'Brien L, Kerrigan SW, Kaw G, Hogan M, Penadés J, Litt D, Fitzgerald DJ, Foster TJ, Cox D: Multiple mechanisms for the activation of human platelet aggregation by Staphylococcus aureus: roles for the clumping factors ClfA and ClfB, the serine-aspartate repeat protein SdrE and protein A. Mol Microbiol 2002, 44:1033-1044.

23. Dale SE, Doherty-Kirby A, Lajoie G, Heinrichs DE: Role of siderophore biosynthesis in virulence of Staphylococcus aureus: identification and characterization of genes involved in production of a siderophore. Infect Immun 2004, 72:29-37.

24. Alba-Loureiro TC, Hirabara SM, Mendonca JR, Curi R, Pithon-Curi TC: Diabetes causes marked changes in function and metabolism of rat neutrophils. J Endocrinol 2006, 188:295-303.

25. Lee JC, Park JS, Shepherd SE, Carey V, Fattom A: Protective efficacy of antibodies to the Staphylococcus aureus type 5 capsular polysaccharide in a modified model of endocarditis in rats. Infect Immun 1997, 65:4146-4151

26. Beenken KE, Dunman PM, McAleese F, Macapagal D, Murphy E, Projan SJ, Blevins JS, Smeltzer MS: Global gene expression in Staphylococcus aureus biofilms. J Bacteriol 2004, 186:4665-4684.

27. Dale SE, Sebulsky MT, Heinrichs DE: Involvement of SirABC in iron-siderophore import in Staphylococcus aureus. J Bacterio/ 2004, 186:8356-8362.

28. Beasley FC, Vines ED, Grigg JC, Zheng Q, Liu S, Lajoie GA, Murphy ME, Heinrichs DE: Characterization of staphyloferrin A biosynthetic and transport mutants in Staphylococcus aureus. Mol Microbiol 2009, 72:947-963.

29. Ding Y, Fu Y, Lee JC, Hooper DC: Staphylococcus aureus NorD, a putative efflux pump coregulated with the Opp1 oligopeptide permease, contributes selectively to fitness in vivo. J Bacteriol 2012, 194:6586-6593.

30. Kehl-Fie TE, Zhang Y, Moore JL, Farrand AJ, Hood MI, Rathi S, Chazin WJ, Caprioli RM, Skaar EP: MntABC and MntH contribute to systemic Staphylococcus aureus infection by competing with calprotectin for nutrient manganese. Infect Immun 2013, 81:3395-3405.

31. Procopio Evagrio George N, Wei Q, Kyun Shin P, Konstantopoulos K, Ross JM: Staphylococcus aureus adhesion via Spa, ClfA, and SdrCDE to immobilized platelets demonstrates shear-dependent behavior. Arterioscler Thromb Vasc Biol 2006, 26:2394-2400.

32. Palazzolo-Ballance AM, Reniere ML, Braughton KR, Sturdevant DE, Otto M, Kreiswirth BN, Skaar EP, DeLeo FR: Neutrophil microbicides induce a pathogen survival response in community-associated methicillinresistant Staphylococcus aureus. J Immunol 2008, 180:500-509.

33. Weinrick B, Dunman PM, McAleese F, Murphy E, Projan SJ, Fang Y, Novick RP: Effect of mild acid on gene expression in Staphylococcus aureus. J Bacteriol 2004, 186:8407-8423.

34. Resch A, Rosenstein R, Nerz C, Gotz F: Differential gene expression profiling of Staphylococcus aureus cultivated under biofilm and planktonic conditions. Appl Environ Microbiol 2005, 71:2663-2676.

35. Malachowa N, Whitney AR, Kobayashi SD, Sturdevant DE, Kennedy AD, Braughton KR, Shabb DW, Diep BA, Chambers HF, Otto M, DeLeo FR: Global changes in Staphylococcus aureus gene expression in human blood. PLoS One 2011, 6:e18617.

36. Voyich JM, Braughton KR, Sturdevant DE, Whitney AR, Said-Salim B, Porcella SF, Long RD, Dorward DW, Gardner DJ, Kreiswirth BN, Musser JM, DeLeo FR: Insights into mechanisms used by Staphylococcus aureus to avoid destruction by human neutrophils. J Immunol 2005, 175:3907-3919.

37. Diep BA, Palazzolo-Ballance AM, Tattevin P, Basuino L, Braughton KR, Whitney AR, Chen L, Kreiswirth BN, Otto M, DeLeo FR, Chambers HF: Contribution of Panton-Valentine leukocidin in community-associated methicillin-resistant Staphylococcus aureus pathogenesis. PLoS One 2008, 3:e3198.

38. Pohl K, Francois P, Stenz L, Schlink F, Geiger T, Herbert S, Goerke C, Schrenzel J, Wolz C: CodY in Staphylococcus aureus: a regulatory link between metabolism and virulence gene expression. J Bacterio/ 2009, 191:2953-2963.

39. Baba T, Bae T, Schneewind O, Takeuchi F, Hiramatsu K: Genome sequence of Staphylococcus aureus strain Newman and comparative analysis of staphylococcal genomes: polymorphism and evolution of two major pathogenicity islands. J Bacterio/ 2008, 190:300-310.

40. Grundmeier M, Hussain M, Becker P, Heilmann C, Peters G, Sinha B: Truncation of fibronectin-binding proteins in Staphylococcus aureus strain Newman leads to deficient adherence and host cell invasion due to loss of the cell wall anchor function. Infect Immun 2004, 72:7155-7163.

41. Geiger T, Goerke C, Mainiero M, Kraus D, Wolz C: The virulence regulator Sae of Staphylococcus aureus: promoter activities and response to phagocytosis-related signals. J Bacteriol 2008, 190:3419-3428.
42. Herbert S, Ziebandt AK, Ohlsen K, Schafer T, Hecker M, Albrecht D, Novick R, Gotz F: Repair of global regulators in Staphylococcus aureus 8325 and comparative analysis with other clinical isolates. Infect Immun 2010, 78:2877-2889.

43. Wolz C, Goerke C, Landmann R, Zimmerli W, Fluckiger U: Transcription of clumping factor A in attached and unattached Staphylococcus aureus in vitro and during device-related infection. Infect Immun 2002, 70:2758-2762.

44. Schennings T, Heimdahl A, Coster K, Flock Jl: Immunization with fibronectin binding protein from Staphylococcus aureus protects against experimental endocarditis in rats. Microb Pathog 1993, 15:227-236.

45. Siboo IR, Cheung AL, Bayer AS, Sullam PM: Clumping factor A mediates binding of Staphylococcus aureus to human platelets. Infect Immun 2001, 69:3120-3127.

46. Baddour LM, Lowrance C, Albus A, Lowrance JH, Anderson SK, Lee JC: Staphylococcus aureus microcapsule expression attenuates bacterial virulence in a rat model of experimental endocarditis. J Infect Dis 1992, 165:749-753.

47. Watts A, Ke D, Wang Q, Pillay A, Nicholson-Weller A, Lee JC: Staphylococcus aureus strains that express serotype 5 or serotype 8 capsular polysaccharides differ in virulence. Infect Immun 2005, 73:3502-3511.

48. Wacker M, Wang L, Kowarik M, Dowd M, Lipowsky G, Faridmoayer A, Shields K, Park S, Alaimo C, Kelley KA, Braun M, Quebatte J, Gambillara V, Carranza P, Steffen M, Lee JC: Prevention of Staphylococcus aureus infections by glycoprotein vaccines synthesized in Escherichia coli. J Infect Dis 2014, 209:1551-1561

49. Koprivnjak T, Mlakar V, Swanson L, Fournier B, Peschel A, Weiss JP: Cation-induced transcriptional regulation of the dlt operon of Staphylococcus aureus. J Bacteriol 2006, 188:3622-3630.

50. Yang S-J, Kreiswirth BN, Sakoulas G, Yeaman MR, Xiong YQ, Sawa A, Bayer AS: Enhanced expression of dItABCD Is associated with the development of daptomycin nonsusceptibility in a clinical endocarditis isolate of Staphylococcus aureus. J Infect Dis 2009, 200:1916-1920.

51. Levine DP, Lamp KC: Daptomycin in the treatment of patients with infective endocarditis: experience from a registry. Am J Med 2007, 120:S28-S33.

52. Sakoulas G, Eliopoulos GM, Alder J, Eliopoulos CT: Efficacy of daptomycin in experimental endocarditis due to methicillin-resistant Staphylococcus aureus. Antimicrob Agents Chemother 2003, 47:1714-1718.

53. Sieprawska-Lupa M, Mydel P, Krawczyk K, Wojcik K, Puklo M, Lupa B, Suder P, Silberring J, Reed M, Pohl J, Shafer W, McAleese F, Foster T, Travis J, Potempa J: Degradation of human antimicrobial peptide LL-37 by Staphylococcus aureus-derived proteinases. Antimicrob Agents Chemother 2004, 48:4673-4679.

54. Boles BR, Horswill AR: Agr-mediated dispersal of Staphylococcus aureus biofilms. PLOS Pathog 2008, 4:e1000052.

55. Kaneko J, Kamio Y: Bacterial two-component and hetero-heptameric pore-forming cytolytic toxins: structures, pore-forming mechanism, and organization of the genes. Biosci Biotechnol Biochem 2004, 68:981-1003.

56. Cheung J, Beasley FC, Liu S, Lajoie GA, Heinrichs DE: Molecular characterization of staphyloferrin B biosynthesis in Staphylococcus aureus. Mol Microbiol 2009, 74:594-608.

57. Skaar EP, Humayun M, Bae T, DeBord KL, Schneewind O: Iron-source preference of Staphylococcus aureus infections. Science 2004, 305:1626-1628.

58. Speziali CD, Dale SE, Henderson JA, Vines ED, Heinrichs DE: Requirement of Staphylococcus aureus ATP-binding cassette-ATPase FhuC for ironrestricted growth and evidence that it functions with more than one iron transporter. J Bacteriol 2006, 188:2048-2055.

59. Mishra R, Mariotti P, Fiaschi L, Nosrai S, Maccari S, Liberatori S, Fontana M, Pezzicoli A, De Falco M, Falugi F, Altindis E, Serruto D, Grandi G, Bagnoli F: Staphylococcus aureus FhuD2 is involved in the early phase of staphylococcal dissemination and generates protective immunity in mice. J Infect Dis 2012, 206:1041-1049.

60. Truong-Bolduc QC, Hsing LC, Villet R, Bolduc GR, Estabrooks Z, Taguezem GF, Hooper DC: Reduced aeration affects the expression of the NorB efflux pump of Staphylococcus aureus by posttranslational modification of MgrA. J Bacteriol 2012, 194:1823-1834.

61. Sitkiewicz I, Babiak I, Hryniewicz W: Characterization of transcription within sdr region of Staphylococcus aureus. Antonie Van Leeuwenhoek 2011, 99:409-416. 
62. Barbu EM, Ganesh VK, Gurusiddappa S, Mackenzie RC, Foster TJ, Sudhof TC, Höök M: $\beta$-Neurexin is a ligand for the Staphylococcus aureus MSCRAMM SdrC. PLoS Pathog 2010, 6:e1000726.

63. Makhlin J, Kofman T, Borovok I, Kohler C, Engelmann S, Cohen G, Aharonowitz Y: Staphylococcus aureus ArcR controls expression of the arginine deiminase operon. J Bacteriol 2007, 189:5976-5986.

64. Leibig M, Liebeke M, Mader D, Lalk M, Peschel A, Götz F: Pyruvate formate lyase acts as a formate supplier for metabolic processes during anaerobiosis in Staphylococcus aureus. J Bacteriol 2011, 193:952-962.

65. Ballal A, Manna AC: Regulation of superoxide dismutase (sod) Genes by SarA in Staphylococcus aureus. J Bacteriol 2009, 191:3301-3310.

66. Xiong YQ, Van Wamel W, Nast CC, Yeaman MR, Cheung AL, Bayer AS: Activation and transcriptional interaction between agr RNAll and RNAlll in Staphylococcus aureus in vitro and in an experimental endocarditis model. J Infect Dis 2002, 186:668-677.

67. Torres VJ, Attia AS, Mason WJ, Hood MI, Corbin BD, Beasley FC, Anderson $\mathrm{KL}$, Stauff DL, McDonald WH, Zimmerman LJ, Friedman DB, Heinrichs DE, Dunman PM, Skaar EP: Staphylococcus aureus Fur regulates the expression of virulence factors that contribute to the pathogenesis of pneumonia. Infect Immun 2010, 78:1618-1628.

68. Pietiainen M, Francois P, Hyyrylainen HL, Tangomo M, Sass V, Sahl HG, Schrenzel J, Kontinen VP: Transcriptome analysis of the responses of Staphylococcus aureus to antimicrobial peptides and characterization of the roles of vraDE and vraSR in antimicrobial resistance. BMC Genomics 2009, 10:429.

69. Yang J, Tauschek M, Robins-Browne RM: Control of bacterial virulence by AraC-like regulators that respond to chemical signals. Trends Microbiol 2011, 19:128-135.

70. Seidl K, Muller S, Francois P, Kriebitzsch C, Schrenzel J, Engelmann S, Bischoff M, Berger-Bachi B: Effect of a glucose impulse on the CcpA regulon in Staphylococcus aureus. BMC Microbiol 2009, 9:95.

doi:10.1186/s13073-014-0093-3

Cite this article as: Hanses et al: Staphylococcus aureus gene expression in a rat model of infective endocarditis. Genome Medicine 2014 6:93.

\section{Submit your next manuscript to BioMed Central and take full advantage of:}

- Convenient online submission

- Thorough peer review

- No space constraints or color figure charges

- Immediate publication on acceptance

- Inclusion in PubMed, CAS, Scopus and Google Scholar

- Research which is freely available for redistribution 